\title{
Performance of long term glass-grid test section in Warsaw
}

\author{
Maciej Maliszewski, Przemysław Harasim, Dominika Maliszewska, Adam Zofka \\ Road and Bridge Research Institute, 1, Instytutowa str, 03-302 Warsaw,Poland
}

\begin{abstract}
This paper presents the study that investigated the performance of the glass-grid reinforced trial pavement sections. Considered test section was constructed in 2001 in the city of Warsaw during the full-depth reconstruction. The section was sub-divided into two parts: one subsection had an installation of the glass-grid between asphalt sub-base and asphalt binder course, while the other subsection was the control pavement without the any reinforcement. Performance and effectiveness of the reinforcement was evaluated in in 4-year intervals between 2004 and 2012. The evaluation of data comprised the FWD maximum deflection comparison as well as deflection bowl geometry analysis. Additionally, the Traffic Speed Deflectometer (TSD) device was used to assess the pavement condition in 2013. The bowl geometry analysis was conducted using an unique approach in which the deflection bowl was subdivided into 3-point segments and an arch was circumscribed into each segment. Reinforced sections were characterized by statistically higher values of the arch radiuses than the unreinforced sections which could be considered as the measureable reinforcing effect of glass-grid on the pavement fatigue life. Maximum deflections growth in year-to-year comparison was higher on the unreinforced section as well as more deteriorations were observed on the unreinforced section. The TSD measurements were also compared between two subsections and analyzed in terms of the calculated deflections.
\end{abstract}

Keywords: glass-grid reinforcement; Falling Weight Deflectometer; Traffic Speed Deflectometer; trial pavement section.

\section{Nomenclature}

A FWD - "Falling Weigh Deflectometer"

Nowadays Falling Weight Deflectometer (FWD) is the most common non-destructive device for the bearing capacity assessment. Different types of pavements are evaluated during and after the construction, such as typical roads and city streets, airport pavements, but also large industrial surfaces. The analysis of load capacity is made on the basis of deflection bowl measurements. The pavement deflection caused by the load is measured with the use of sensors - geophones, which are situated in the pressure centre (plate bearing device) and in certain distances from the central point (e.g. 300, 600, 900, 1200,1500 and $1800 \mathrm{~mm}$ ). Knowing the pavement construction and the depth and shape of deflection bowl, the pavement condition can be assessed. During routine measurement FWD device simulates the pressure made by a truck moving at a speed of $3540 \mathrm{~km} / \mathrm{h}$ but it has the ability to apply the maximum force of $120 \mathrm{kN}$.

B TSD - "Traffic Speed Deflectometer" (explained in text);

C maximum deflection, deflection bowl and hypothetical radius of deflection curve;

D asphalt - mixture of bitumen, filler, aggregates, additives conforming with receipt.

\section{Introduction}

\subsection{General}

Many types of geosynthetics, which are mean to reinforce asphalt layers, are available on the market. On the other hand it is difficult to choose an optimal assessment method of their effectiveness. The reinforcing capabilities are varying by product type (grid, composite, nonwoven), raw materials (mineral fibres, polymers, steel rods, etc.), as well as by the type of aperture. Quality of application process and product location in a pavement construction pay significant role. These complex characteristics of the material are contrasting the development of the universal design method of asphalt layers reinforced using geosynthetics. Actually, the most reasonable method of reassessment is the indirect, instrumented evaluation of such constructions [1]. This paper describes a specific assessment method of the long-term influence of the glass geogrid on the

Corresponding author: Maciej Maliszewski. E-mail address: mmaliszewski@ibdim.edu.pl

http://dx.doi.org/10.3846/enviro.2014.160

(C) 2014 The Authors. Published by VGTU Press. This is an open-access article distributed under the terms of the Creative Commons Attribution License, which permits unrestricted use, distribution, and reproduction in any medium, provided the original author and source are credited. 
asphalt pavement. This project was partly funded within the scope of SPENS Project ( $6^{\text {th }}$ Framework Program) [2], and the Road and Bridge Research Institute (IBDiM) research budget.

\subsection{Geosynthetic}

Following the Polish road construction practice [3], [4] the main goal of geosynthetic application between the asphalt layers is to mitigate the probability of fatigue cracking propagation. This treatment is mainly applied in pavements consisting of flexible sub-base and/or weak subgrade when there is a high risk of deflections exceeding the threshold levels. If the rigid sub-base is present, geosynthetic application is intended to reduce the propagation of reflective cracking. In both cases, geosynthetics play their role only if they are placed in tension stress area while pavement is loaded by wheel or sub-base shrinkage occurs. In order to meet these objectives, the following conditions should be met:

- location of geosynthetic close to the bottom of asphalt layers;

- use of high stiffness modulus geosynthetic;

- good geosynthetic bonding with asphalt layers;

- pre-tensioning during installation of geosynthetic.

Theoretically these assumptions are considered during the construction process. However, the real results of the geosynthetic effectiveness can be only proven on the basis of the long term observations or "in situ" test results which is the main focus of this paper.

Considered here, the glass grid, is one of many types of the reinforcement used in the road construction. Its functions are mainly described as to improve pavement fatigue life, rutting resistance and reflective cracking propagation. In this project, pavement was reinforced with a grid made of glass fibres (so called glass-grid). The grid was characterized with $35 \mathrm{kN} / \mathrm{m}$ ultimate strength and less than 3\% ultimate strain. Nowadays, glass-grids are produced to reach higher strength levels, but in 2001 it was a standard type.

\subsection{Test section}

Test section was established on eastern carriageway of Marszałkowska Street in Warsaw. Marszałkowska Street was deep reconstructed in 2001, between crossings with Piękna Street and Nowogrodzka Street. Old pavement was overhauled and replaced with the flexible pavement construction which is presented in Table 1.

Table 1. Pavement typical section on Marszałkowska Street

\begin{tabular}{lll}
\hline Layer / course & Material & Thickness (cm) \\
\hline Wearing course & AC $16 \mathrm{PmB}$ & 5 \\
Binder course & AC $20 \mathrm{PmB}$ & 5 \\
Reinforcing grid* & Glass fibre & ca. 0,5 \\
Sub-base & AC 32 35/50 & 9 \\
Sub-base & mechanical stabilization & 25 \\
Anti-frost layer & all-in aggregate & 20 \\
Non-woven* & polypropylene & ca. 0,5 \\
Subgrade & aggregate & $10 \mathrm{~cm}$ \\
\hline
\end{tabular}

* present only on half of test section, called in this paper - reinforced section

Every layer above granular sub-base was tack coated using asphalt cationic emulsion. The total length of the reconstruction was approx. $700 \mathrm{~m}$. It was divided into two subsections, each $350 \mathrm{~m}$ long. Primary subsection between Piękna Street and Hoża Street contained the installation of glass-grid between asphalt sub-base and asphalt binder course and nonwoven on top of subgrade. Accordingly, that subsection is called reinforced section in this paper while the second section, between Hoża Street and Nowogrodzka Street, will be named unreinforced section.

\section{Methodology}

\subsection{Theory and assumptions for FWD measurements}

The main problem of asphalt layers reinforcement effectiveness evaluation in first years after construction is a lack of visual performance indicators. More advanced methods should be used. Theoretical models predict behaviour of pavement, but must be calibrated [5]. Direct type measurements using stress and strain gauges are more accurate to evaluate pavement condition, but are more time and cost consuming, comparing to indirect pavement condition evaluation methods.

In this research project the reinforcing effect of glass-grid application was evaluated using the FWD [6]. The FWD produces test results comprising applied stress conditions, as well as pavement response in terms of shape of the deflection bowl. Two types of data were evaluated - maximum deflections and deflection bowl geometry together with corresponding 
indices. Maximum deflections under load plate indicate the general pavement condition and remaining fatigue life that can be expressed in e.g. equivalent axle loadings. The higher maximum pavement deflections are recognized, the less load axles this pavement can bear.

Initial analysis showed nearly no influence of reinforcement on the maximum deflections of pavement, indicating statistically equal mean deflections under load plate on both reinforced and unreinforced sections. While positive reinforcement effects are recognized and proved by observations, there are almost no evidence of their positive influence confirmed by direct tests performed on real, reinforced pavement. Usually the misleading test results were explained as caused by inhomogeneous subgrade or construction, improper installation of reinforcement or errors during the measurements. This was the motivation to apply more advanced approach in order to evaluate the pavement reinforcement effect.

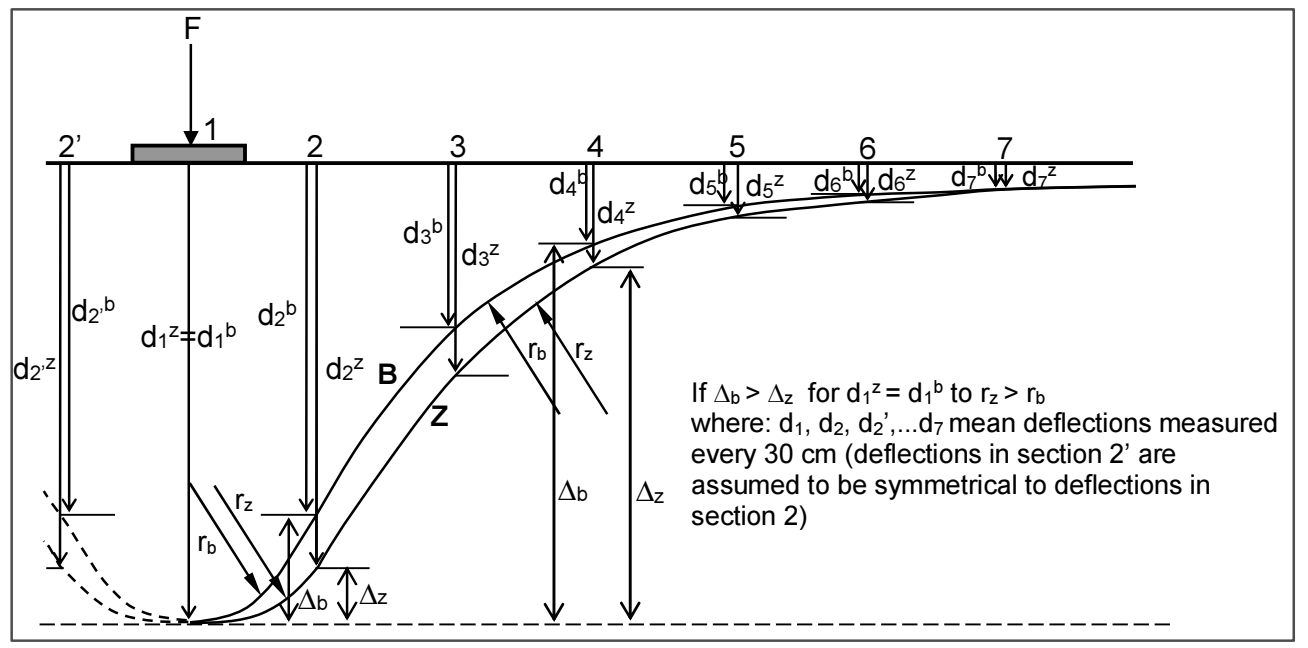

Fig. 1. Definition of terms

The research was to verify if application of grid on reinforced section resulted in change of maximum deflections under load plate, deflection curve shape and how these parameters were changing in time. The assumption was that when comparing a pair of single FWD measurements indicating the same maximum deflections, the reinforced pavement deflection curvature should have greater radius. It applies to both horizontal plane or vertical section (Fig. 1). In order to simplify the comparison, the cross-section of deflection bowl was divided into the segments comprising three consecutive points (measurements). The coordinates (span and deflection value) of measurement points were known, so the arch of known radius could be circumscribed between them. In further considerations if the arch was named as $d_{1}-d_{3}$ it means that it was circumscribed between measurements taken from geophone 1,2 and 3. The only exception was made in case of arch $\mathrm{d}_{2-}$ $\mathrm{d}_{2}$, where the arch is circumscribed between geophone 2, 1 and 2 mirrored by 1 (that is why it was called 2'). Such a notation helped to compare both reinforced and unreinforced sections by radius values.

\subsection{TSD measurements}

TSD measurement is conducted by means of loaded wheel and set of Doppler's laser gauges (Fig. 1). Detectors measure constantly the speed of pavement deflection shape under dynamic load. The load is applied by rear axle of the dual-wheel trolley and equal to $100 \mathrm{kN}$. Pavement deflection speed is translated into pavement deflection basin shape.

The main use for TSD is network-level deflection measurements. According to equipment construction, it is built-up on a truck with semitrailer. Required truck speed during measurements is not less than $38 \mathrm{~km} / \mathrm{h}$, so measurements in urban area are difficult. 


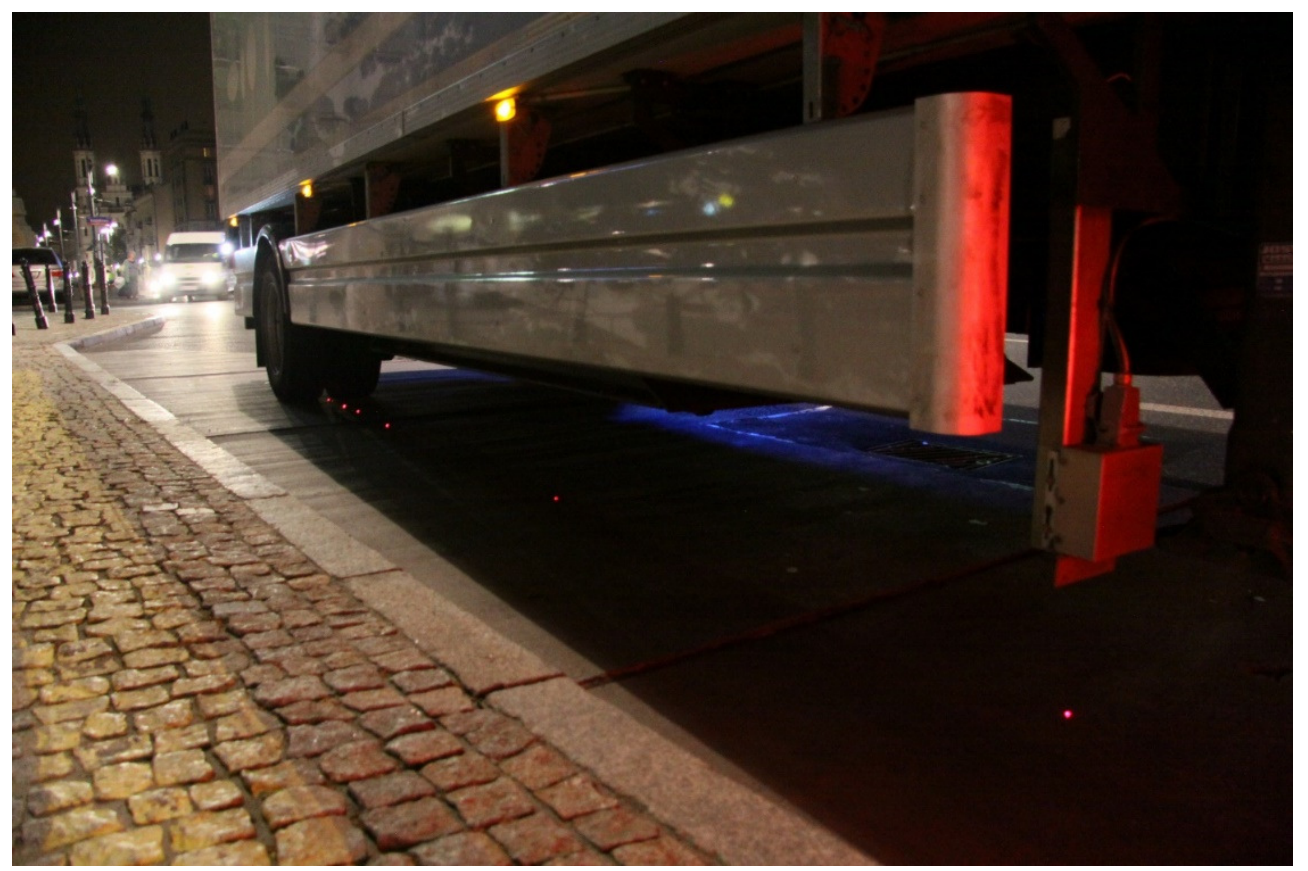

Fig. 2. Laser TSD measuring set ready for testing

\subsection{Measurement campaign}

FWD measurements were conducted in four year cycles, from 2004 [7] to 2012. Measurements took place in the same season of year, before seasonal precipitation. FWD deflection measurements were performed on reinforced and unreinforced subsections, on every of three lanes, with the spacing between test cross sections of $25 \mathrm{~m}$. Two test loads were used, $50 \mathrm{kN}$ and $80 \mathrm{kN}$ to obtain wider spectrum of deflections. Every measurements were performed during one evening. In total 168 measurements were achieved in each campaign (3 lanes, 2 loads, 28 stations). Single measurement data comprised actual contact pressure, load value and deflection values under every of seven geophones (2004) or nine geophones (2008 and 2012). In 2013 there were additional FWD and TSD measurements done, using the schema of previous measurement campaigns.

\subsection{Visual pavement description}

Pavement condition was assessed in 2008 using standard visual method according to SOSN [8]. Pavement condition was inspected visually and all deteriorations were recorded. In 2012 automated pavement distress collection technique were utilized. System comprising cameras and optical detectors recorded pavement surface and then deteriorations were automatically detected and categorized by appropriate software, with supervision of operator.

\section{Analysis}

\subsection{Presentation of deflection basin}

Characteristics of deflection basins on test section is presented in Fig. 3. This figure shows the difference between 2004 and 2012 measurements in terms of deflection distribution along section chainage and in offset from load plate. The predicted difference in deflections evolution was confirmed by this experimental data. First measurements in 2004 characterized themselves with lower values, particularly on unreinforced subsection. Last measurements in 2012 showed higher increase of deflections on unreinforced subsection (indicated by the red areas in Fig. 3). 

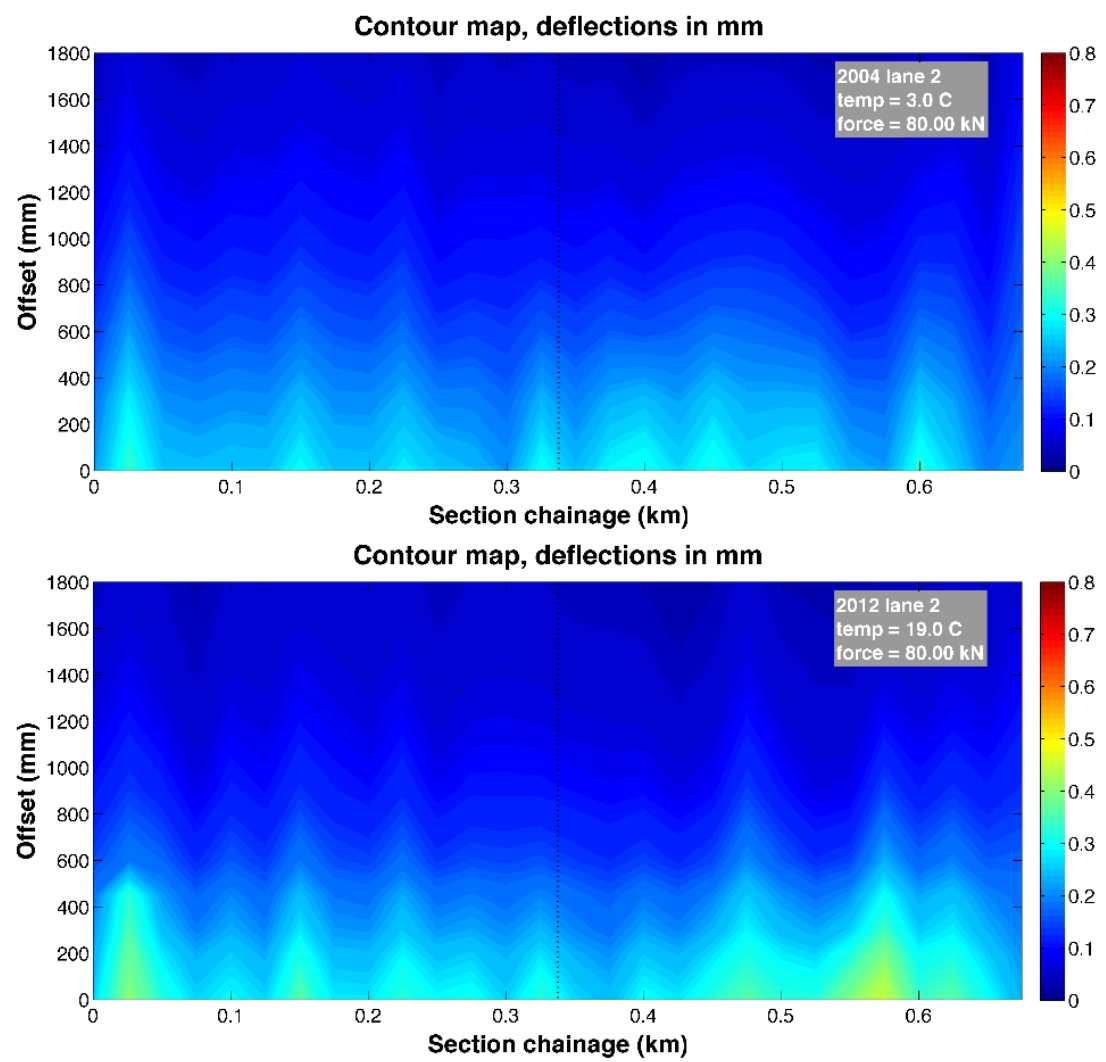

a)

b)

Fig. 3. Experimental data of pavement deflection basin: $\mathrm{a}-2004 ; \mathrm{b}-2012$ (reinforced section is between 0 and $0,350 \mathrm{~km}$ )

\subsection{Comparison of maximum deflections}

If it is assumed that geosynthetic built-in between the asphalt layers reduces fatigue cracking of pavement, it will reduce maximum deflections under wheel load and/or enlarge the curvature radius, comparing to the unreinforced pavement. The 2004 deflection results showed some differences between sections but they were not statistically significant. The difference in maximum deflections between reinforced and unreinforced pavement became significant in 2008 and 2012 measurement campaign. Additional observation was that deflections increase was higher on lane 1 (right-hand lane), which is typically subjected to the heavier traffic loads. The set of comparison charts are shown in Fig. 4. Worth mentioning is that in 2013 measuring campaign appeared a year-to-year decrease of maximum deflections.

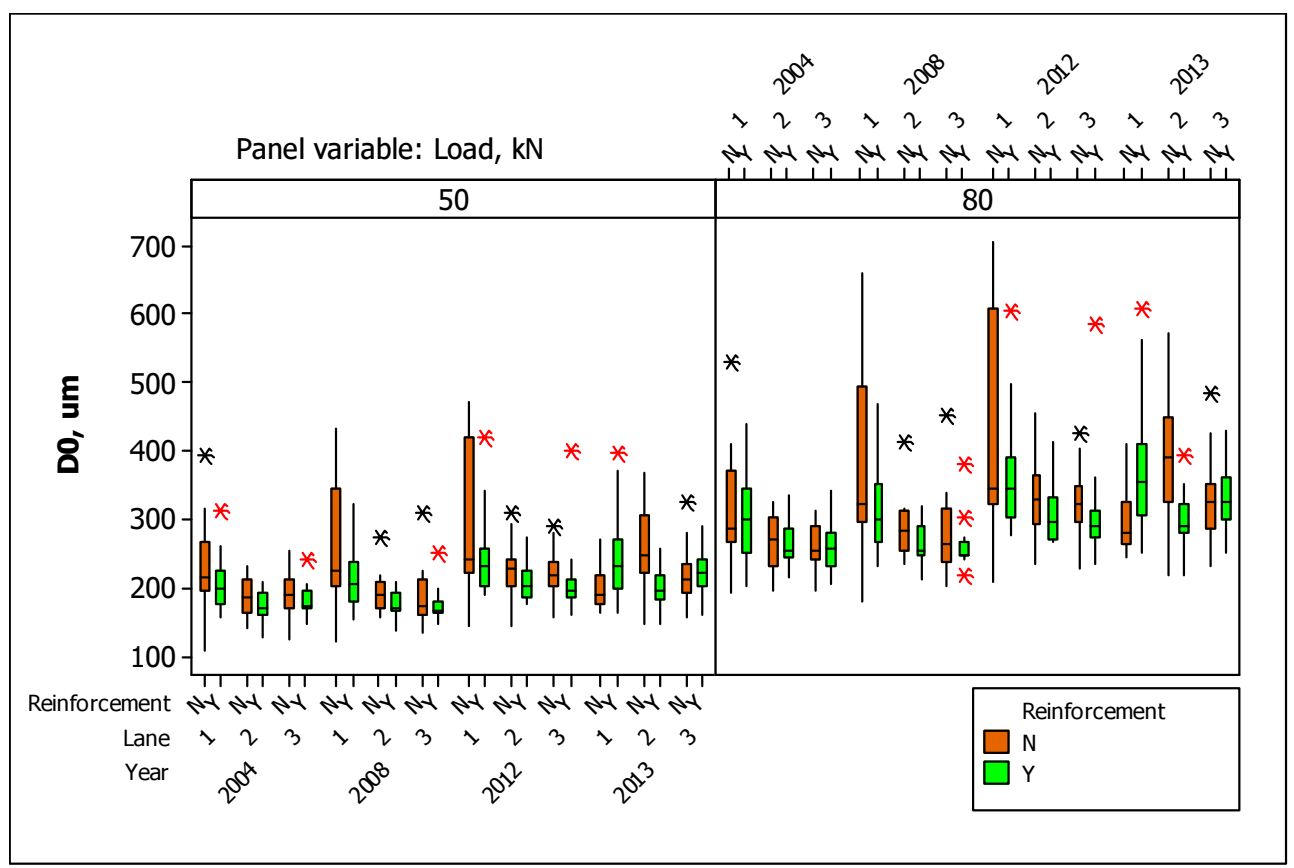

Fig. 4. Comparison of maximum deflections, D0 in time and location 


\subsection{Radiuses analysis}

In this analysis the deflection curve was divided in eight sections comprising every three neighboring points. Between every three points there was a circumscribed circle. Results from three measurement campaigns were shown in Fig. 5. It can be concluded that increase in radius values can be noticed in almost every section of deflection basin comparing reinforced to unreinforced section. The lowest radius values were noticed in the deflection bowl section located directly under load plate (R-101). This first section had the least radius decrement in 8 years of pavement service. Higher average radiuses were located on the reinforced section. Second deflection bowl section (R012) was evaluated only in 2008 and 2012 and radiuses in this section were over two times higher comparing to the first section. Also second section of deflection basin encountered higher decrement of radius in time. Difference between reinforced and unreinforced section was opposite; higher radiuses were observed on unreinforced section. Third and fourth deflection bowl sections (R123 and R234 accordingly) were similarly evolving in time. Initial 2004 and 2008 reinforced section radiuses were of highest values among whole deflection basin. Also highest radius decrements (with highest confidence level) were observed on the unreinforced section compared to the glass-grid section. In 2012 these two sections of deflection basin showed highest radius decrement (from over $20000 \mathrm{~m}$ to less than $3000 \mathrm{~m}$ ) on both reinforced and unreinforced sections. These sections of deflection curve presented pavement bearing capacity descent over time. Also fifth (R345) and sixth (R456) deflection basin sections presented decrement of radius over time. In this case first seven years of pavement service were assisted by glassgrid reinforcement, which limited the radius value increment. In 2012 radiuses of reinforced and unreinforced sections were equal in this part of deflection basin. Seventh (R567) deflection basin section presented initial growth of radius in 2008 and finally a drop-down in 2012. Similar, the reinforced section was characterized by the higher values of radiuses. Last section of deflection curve (R678) showed different behavior; neither radius value increment over time, nor reinforcement influence on radius were significant.

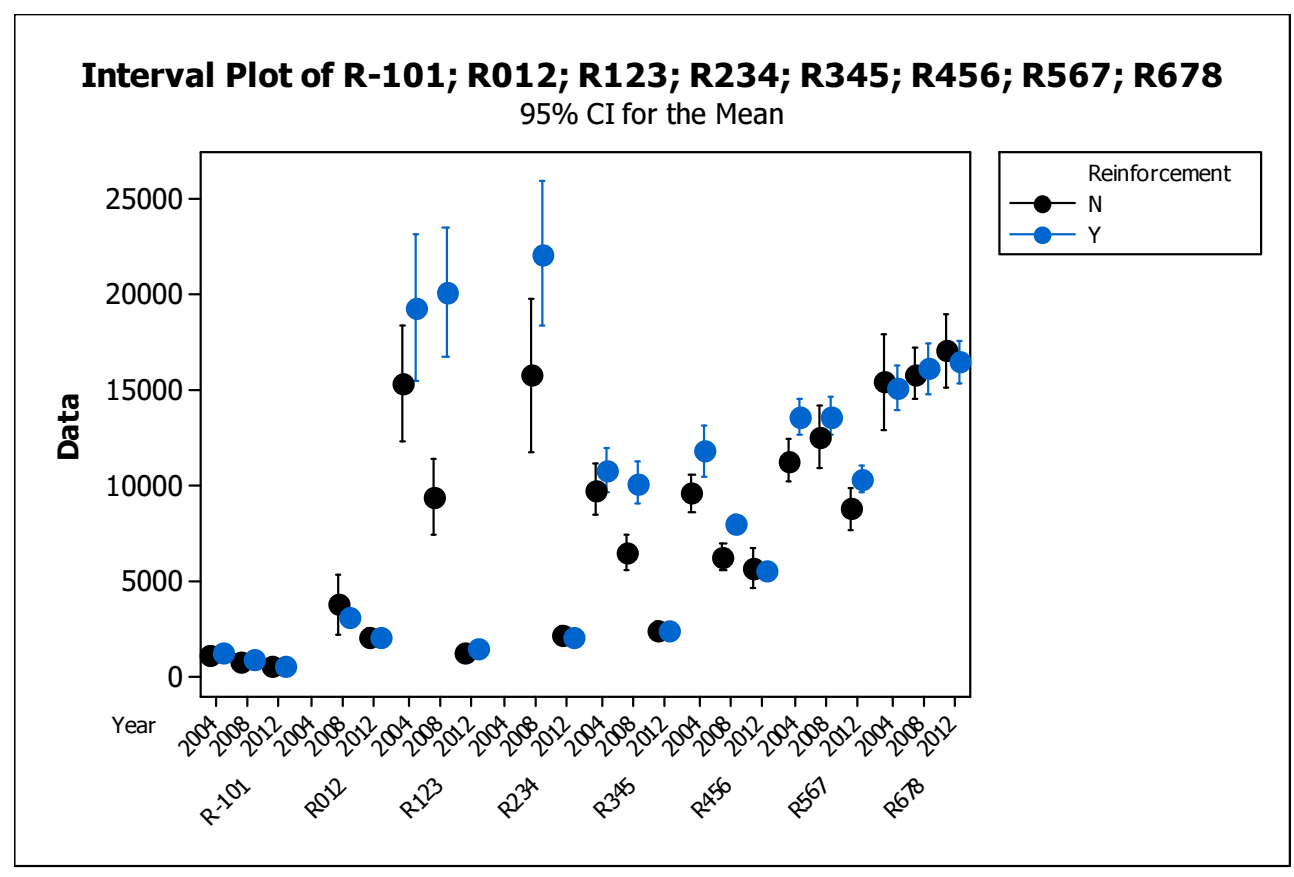

Fig. 5. Evolution of deflection basin radiuses in time

\subsection{FWD and TSD comparison}

First step in preparation of TSD data for evaluation is choice between different measurement bases. For the purpose of this research there were three values considered: $5 \mathrm{~m}, 10 \mathrm{~m}$ and $25 \mathrm{~m}$. The comparison was shown in Fig. 6 . According to graphical data interpretation, the $5 \mathrm{~m}$ measurement step brought to high data span, $25 \mathrm{~m}$ measurement step was insensitive to some characteristic measurement results (A and C). It was decided that in this case, optimal were $10 \mathrm{~m}$ measurement steps. 


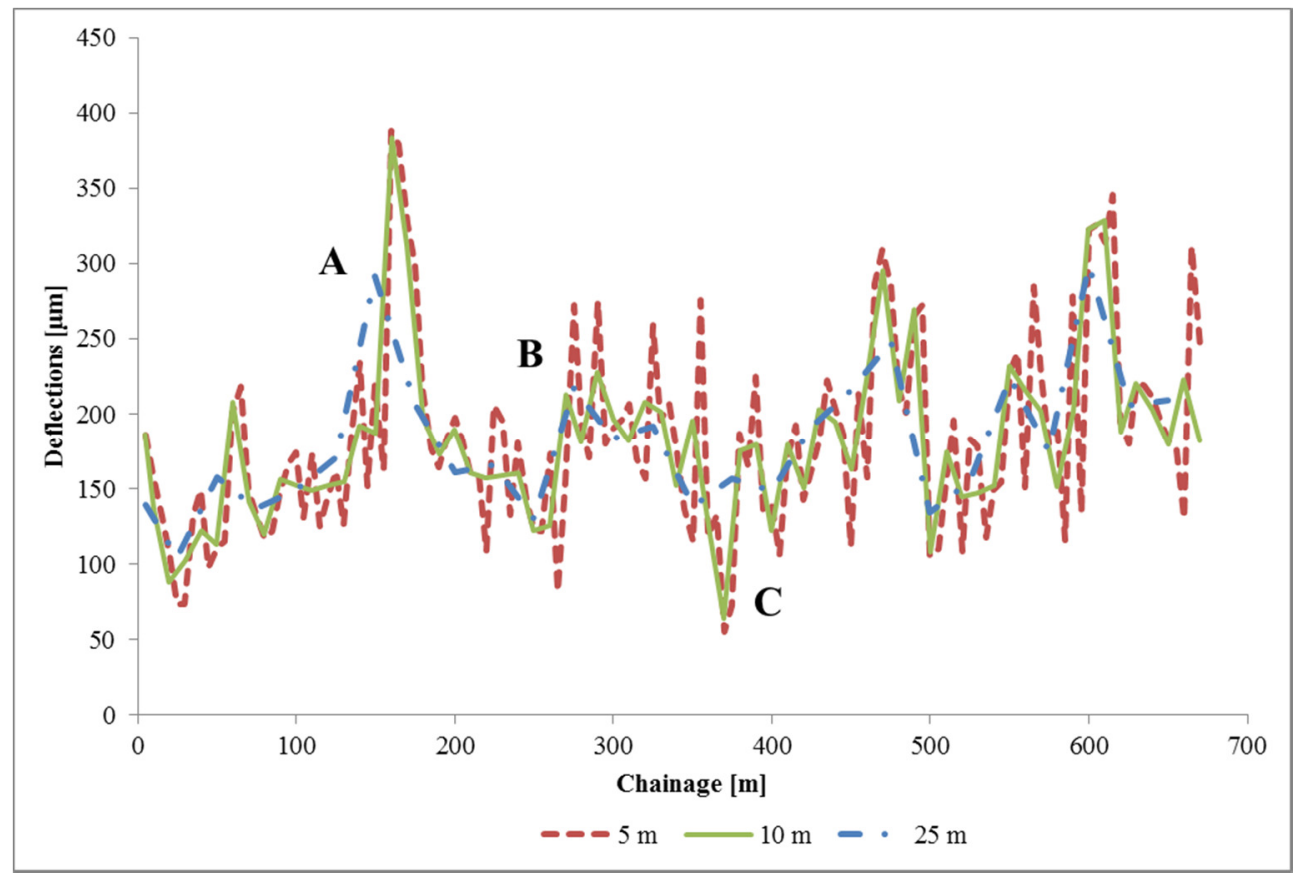

Fig. 6. Comparison of different TSD computation steps

Next, maximum deflection, and deflections under detector located $300 \mathrm{~mm}$ from central detector D300 were presented for 3 lanes separately, and for both deflectometers TSD and FWD (Fig. 7).

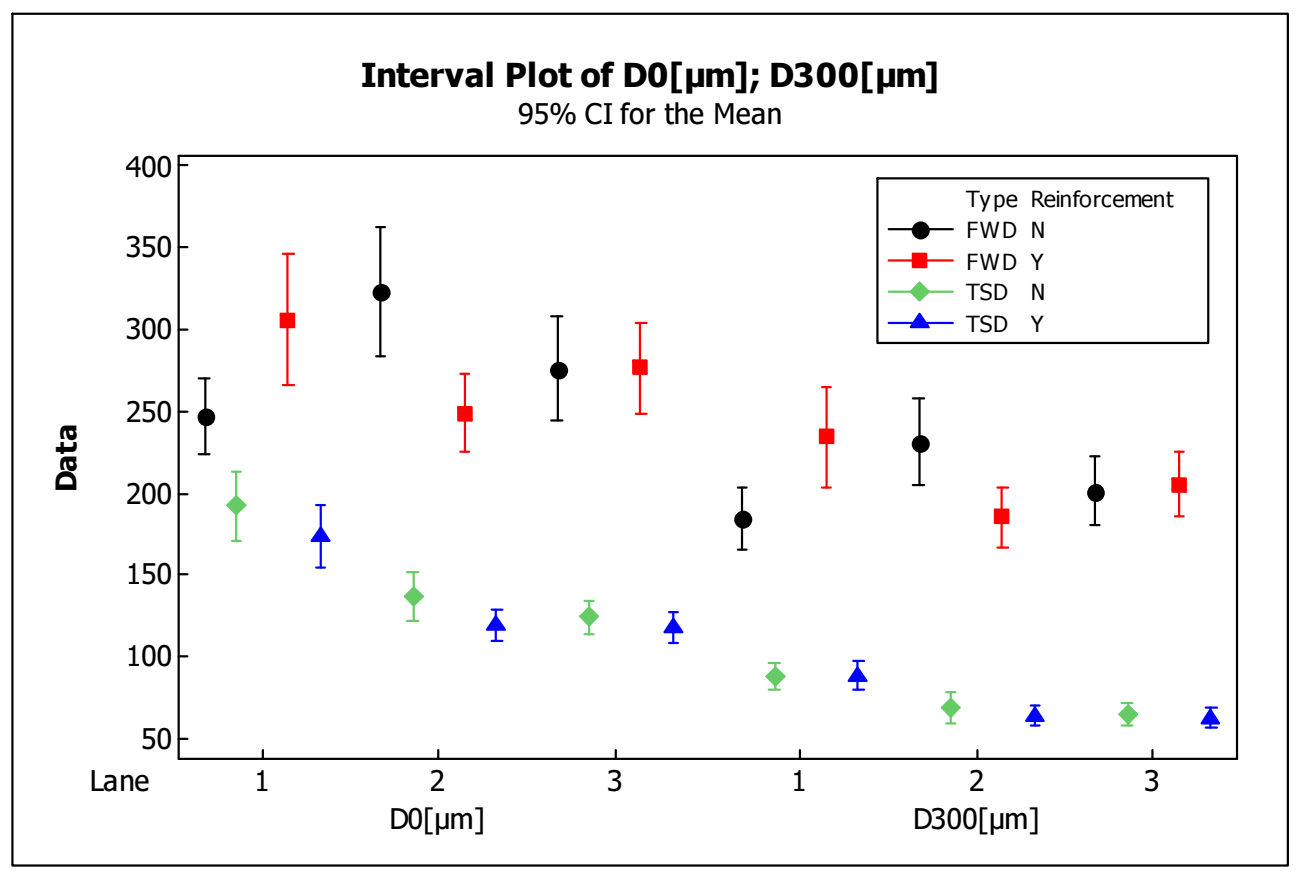

Fig. 7. Results of TSD and FWD measurements

Analyzing TSD data, despite the trend for better performance of reinforced section is visible, measured and computed parameters, D0 and D300, show no significant difference at 95\% confidence interval. FWD parameters were not unite, showing both higher or lower deflections $\mathrm{D} 0$ on reinforced section.

If we compare TSD and FWD measurements respectively, we can notice significant difference between them. FWD measurement values were about 2 times higher as regards D0 values and up to four times higher as regards D300.

\subsection{Visual pavement description}

Pavement inspection results from 2008 and 2012 are described in Table 2. In 2008 minor deteriorations were localized. Inspection indicated that reinforced pavement showed less distresses than unreinforced, but differences were not significant. In 2012 more deteriorations occurred on both sections. In general, deteriorations were not severe. In terms of the bearing 
capacity, significant role play alligator cracks. Majority - two thirds - of them were located on unreinforced section. It should be pointed out that reinforcing grid did not protect the pavement against longitudinal and transversal cracks. It must be emphasized, that pavement was already 11 years old during second visual inspection.

Table 2. Visual inspection results

\begin{tabular}{lll}
\hline Visual inspection campaign & $\begin{array}{l}\text { Deteriorations on reinforced } \\
\text { section }\end{array}$ & $\begin{array}{l}\text { Deteriorations on unreinforced } \\
\text { section }\end{array}$ \\
\hline \multirow{2}{*}{2008} & 1 longitudinal crack $(1 \mathrm{~m})$ & no longitudinal cracks \\
& 2 alligator cracks $(0,5 \mathrm{~m} 2$ total $)$ & 3 alligator cracks $(1,5 \mathrm{~m} 2$ total $)$ \\
& 2 transversal cracks $(1 \mathrm{~m}$ total $)$ & 4 transversal cracks $(11,5 \mathrm{~m}$ total $)$ \\
& 1 patched location $(4 \mathrm{~m} 2)$ & 3 patched locations $(12 \mathrm{~m} 2$ total $)$ \\
\hline \multirow{2}{*}{2012} & 19 longitudinal cracks $(59 \mathrm{~m})$ & 7 longitudinal cracks $(18 \mathrm{~m}$ total $)$ \\
& 14 alligator cracks $(14 \mathrm{~m} 2$ total $)$ & 21 alligator cracks $(21 \mathrm{~m} 2$ total $)$ \\
& 26 transversal cracks $(46 \mathrm{~m}$ total $)$ & 16 transversal cracks $(31 \mathrm{~m}$ total $)$ \\
& 5 patched location $(40 \mathrm{~m} 2)$ & 12 patched locations $(70 \mathrm{~m} 2$ total $)$ \\
\hline
\end{tabular}

\section{Conclusions and recommendations}

This research was generally meant to prove a correlation between use of glass-grid and bearing capacity increase of asphalt flexible pavement. At the beginning of pavement service, the 2004 measurement campaign brought only insignificant change to maximum FWD deflections on reinforced section comparing to reference section. First measurements showed visible and significant difference between deflection basin radiuses on compared sections. After next four years of service, the positive influence of glass-grid appeared in terms of significant pavement deflection reduction. This observation applied mostly to lanes subjected to heavier traffic (center and right lane). Also the influence of reinforcement onto the deflection basin radiuses was most significant. Comparing measurements made on reinforced section in 2004 and 2008, insignificant change of maximum deflections has occurred. The same comparison made on unreinforced section showed significant increase of deflections in the case of lane 1, which was subjected to bus traffic, qualified as heavy. It can be pointed out that influence of reinforcement on deflection value became visible after eight years under traffic. Reinforcement activates as soon as deterioration factors are present (in this case heavy bus traffic). Application of glass-grid between asphalt subbase and binder course in flexible construction resulted in the beneficial increase of deflection curve arc radiuses on the reinforced section while comparing to the unreinforced section.

Maximum deflections increased on reinforced and unreinforced sections, but reinforced section showed main increment. Also in 2012 there was calculated a large drop down of R123 and R234 values and more pavement deteriorations were observed on evaluated pavement. Surface condition was still satisfactory, but some maintenance treatments were needed to keep pavement in good condition. Unreinforced section characterized itself with higher amount of patches and alligator cracks, and reinforced section has higher total length of linear cracks. To sum up in this case reinforcing effect was positive and evaluable for about 10 years.

The 2013 measurement campaign could not be compared quantitatively to 2004-2012 test results, because of year season incompatibility, and resulting with lack of data correlation. In 2013 measurements significantly lower pavement deflections were observed than in 2012. TSD and FWD measurements showed significant differences between deflection measurement results and should not be compared directly.

To sum up, the use of reinforcing grid resulted in increase of deflection bowl arc section radiuses. Higher radiuses of curvature mean that greater area of pavement is involved in cooperation under load. It results in lower bending moments in asphalt layers, which translates to the higher pavement fatigue life. It can be assumed that vulnerability to fatigue, bottomup cracking of pavement was reduced. This positive influence of glass-grids application between asphalt layers is valid unless bond between layers is weakened.

Methodology described in this document should be repeated for other, similar road sections, with different reinforcing materials applied (e.g. made of mineral fibres, steel nets), having different properties from glass-grid applied in tested section. Tests could explain if materials with different parameters lead to the same results as described above. 


\section{References}

[1] Bańkowski, W.; Gajewski, M. 2012. Accelerated real-scale tests of innovative pavements, Roads and Bridges no 2/2012, IBDiM, 89-121.

[2] Maliszewski, M. 2009. Assesment of influence of geosynthetic reinforcement to elastic deflection of flexible pavement. SPENS Semminar, „Sustainable pavements for new member states”, Warsaw, 14.10.2009 r., available from Internet: http://www.ibdim.edu.pl/images/stories/dokumenty/spens/spens\%20mali.pdf

[3] Zawadzki, J.; Skierczyński, P. 2004. Guidelines for use of geosynthetics in asphalt pavements, Copybook 66/2004 Information, Instructions.

[4] Sybilski, D.; Maliszewska, D.; Maliszewski, M. 2011. Experiences with reinforcing grids on Warsaw pavement reconstructions, Construction Materials 3: 79-83.

[5] Jemioło, S.; Gajewski, M.; Mularzuk, R.; Maliszewski, M. 2008. Theoretical models of road meshes and their use in standard pavement designing software, in 4th Euroasfalt \& Eurobitum Congress, Copenhagen, 21-23.05.2008, 468-475.

[6] Davis, T. G.; Mamlouk, M. S. 1985. Theoretical response of Multilayer Pavement Systems to Dynamic Nondestructive Testing, Transportation Research Record 1022: 1-7.

[7] Zawadzki, J.; Maliszewska, D.; Maliszewski, M.; Mechowski, T.; Mularzuk, R. 2007 Pavement reinforcement with use of glass-grid, Drogownictwo 10: 329-333

[8] SOSN, 2002. Polish system of evaluation of pavement condition, General Directoriate for State Roads and Highways

[9] NCHRP Synthesis Report 381, Falling Weight Deflectometer Usage, 2008 